\title{
Structure determination of clinofibrate photoproducts generated by ultraviolet-light irradiation in aqueous media
}

\author{
Kohei Kawabata $^{1}$ (1) $\cdot$ Shiori Akimoto ${ }^{2} \cdot$ Masanori Inagaki $^{1} \cdot$ Hiroyuki Nishi $^{1}$
}

Received: 17 February 2021 / Accepted: 1 June 2021

Published online: 09 June 2021

(c) The Author(s) 2021

OPEN

\begin{abstract}
Photodegradation of clinofibrate, which is one of the fibrate drugs, was evaluated and chemical structures of its photoproducts were determined. Clinofibrate in aqueous media was photodegraded gradually by the UV light emission with the generation of several photoproducts. The result of HPLC analysis indicated that some photoproducts were more photostable compared with the parent compound. After 14 days irradiation, clinofibrate was degraded completely while several photoproducts were remained in the test solution. Structure determination of nine photoproducts was performed by means of ESI-LC/MS/MS analysis. Main photoproduct of clinofibrate was 2-(4-(1-(4-hydroxyphenyl) cyclohexyl)phenoxy)-2-methylbutanoic acid. Structure determination of clinofibrate photoproducts made it possible the estimation of the photodegradation pathway. It was tempting to speculate that the main photoproduct was generated by the elimination of 2-methylbutanoic acid and other photoproducts were generated through several photochemical reactions including further elimination of 2-methylbutanoic acid and decarboxylation. The obtained results will be helpful for the further research focused on the evaluation of biological activities of clinofibrate photoproducts, photostability of clinofibrate in commercial tablets and changed formulations, and the photostabilization of them.
\end{abstract}

Keywords Photoproduct $\cdot$ ESI-LC/MS/MS · Clinofibrate $\cdot$ Photodegradation

\section{Introduction}

It is required for the new drug application to evaluate the stability of the new drug in addition to the evaluation of its efficacy and safety. For achieving this purpose, the Stability Test Guidelines agreed with the International Conference on Harmonization of Technical Requirements for Registration of Pharmaceuticals for Human Use (ICH) have been established (ICH-Q1A). It prescribes the stability tests such as the long-term storage test (under the conditions of $25 \pm 2{ }^{\circ} \mathrm{C}$ and $60 \pm 5 \% \mathrm{RH}$ ), the accelerated test and the severe test (under the condition of $40 \pm 2{ }^{\circ} \mathrm{C}$ and $75 \pm 5 \% \mathrm{RH}$ ) [1]. Especially, the severe test is required to gain the information focused on the change of the quality of the drug induced by the heat, humidity and photo-exposure. The effect of photo-exposure is significant for photosensitive pharmaceuticals [2-6]. In case of the photostability evaluation, it is necessary to conduct the tests based on the ICH guidelines for the photostability evaluation (ICH-Q1B) [7]. These guidelines are necessary for the safety use of pharmaceuticals. On the other hand, ICH guidelines could give limited information

Supplementary Information The online version contains supplementary material available at https://doi.org/10.1007/s42452-02104680-8.

$\checkmark$ Kohei Kawabata, kawabata-k@yasuda-u.ac.jp | ${ }^{1}$ Faculty of Pharmacy, Yasuda Women's University, 6-13-1 Yasuhigashi, Asaminami-ku, Hiroshima 731-0153, Japan. ${ }^{2}$ Graduate School of Biomedical and Health Sciences, Hiroshima University, 1-2-3 Kasumi, Minami-ku, Hiroshima 734-8553, Japan. 
about the photostability of pharmaceuticals because most of photosensitive pharmaceuticals are coated by the polymer and glucose to protect its influence of the photo-exposure. There is no information about the photostability of pharmaceuticals which are crushed and suspended in the interview form.

Photodegradation induces the change of chemical structure and biological activity of the irradiated pharmaceutical. For example, sulfapyridine, which is one of the sulfonamide antibiotics, was degraded by the UV irradiation, and its transformation products were more toxic compared with the parent compound [8]. Various photochemical reactions, including photo-addition, photo-oxidation, photo-cyclization, photo-rearrangement, decarboxylation and dehalogenation, induce the generation of the photoproducts [9-13]. Furthermore, our previous report showed that one of these photochemical reactions, decarboxylation, was occurred in the solid-form of naproxen [14]. It is reported that some photoproducts of naproxen were more ecotoxic compared with the parent compound, under the both acute and chronic conditions $[15,16]$. It is needed to evaluate the photodegradation of photosensitive pharmaceuticals due to that it has a contribution for the residual rate of active compounds in the pharmaceutical and expression of adverse effect. However, photochemical behaviors of most pharmaceuticals are unclear because there are not a lot of studies focused on them.

To gain the information of photodegradation of pharmaceuticals, the photodegradation of clinofibrate (CF) induced by the UV irradiation at longer wavelength was evaluated in this study. CF is a member of the fibrate family. Chemically, it is 2,2'-((cyclohexane-1,1-diylbis (4,1phenylene))bis(oxy))bis(2-methylbutanoic acid) (Fig. 1). Fibrate is a major class of hypolipidemic agent, widely used for therapy in many forms of hypercholesterolemia. It activates peroxisome proliferator activated receptor alpha, which is one of the nuclear receptor and master regulator of the gene expression relating to the lipid metabolism, and improves metabolic disorders. Several studies report the photodegradation of fibrates, including clofibric acid, bezafibrate and fenofibrate [17-19]. However, the photochemical behavior of CF is not evaluated. Firstly, photodegradation rate of CF is examined by means of highperformance liquid chromatography (HPLC). After that, structure determination of generated CF photoproducts is performed by electrospray ionization liquid chromatography mass spectrometry (ESI-LC/MS/MS). The purpose of this study is to evaluate the photostability and photochemical behavior of CF. We hope that the gained results from this experiment will apply the evaluation of photostability of CF in commercial tablets and changed formulations (pulverized powder and suspension), biological

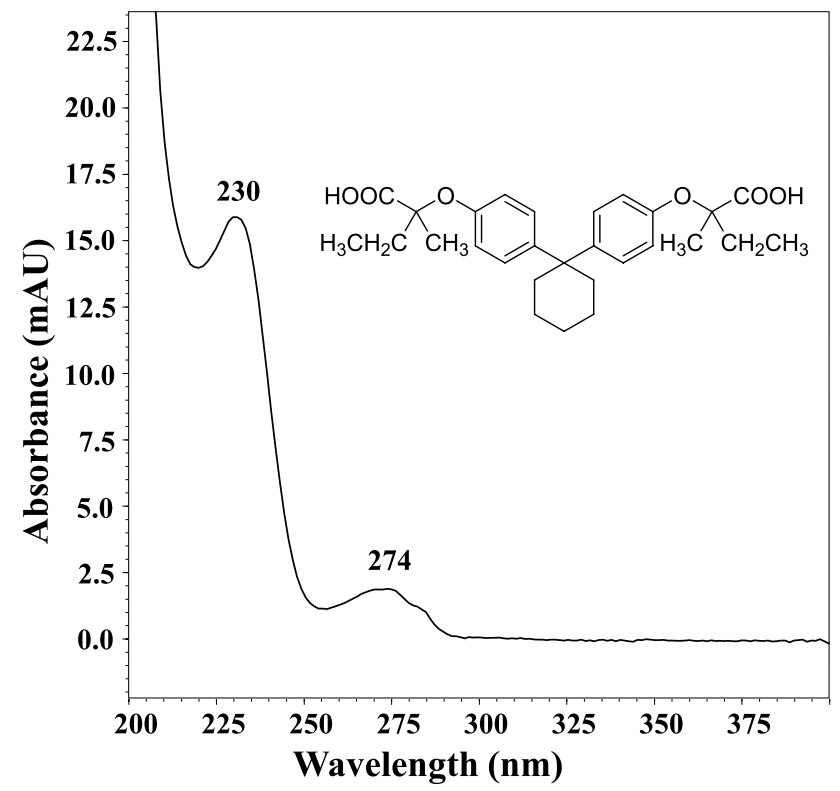

Fig. 1 Chemical structure of CF and its UV absorption spectrum recorded by the PDA detector

activities of CF photoproducts, and photostabilization strategies for CF.

\section{Experimental}

\subsection{Chemicals}

All of reagents and organic solvents used were of special grade or HPLC grade. Clinofibrate (CF), methanol and formic acid were purchased from Fujifilm Wako Pure Chemical Corporation (Osaka, Japan). Milli-Q $(18.2 \mathrm{~m} \Omega / \mathrm{cm})$ water was prepared by using a Milli-Q water purification system (Merck, Darmstadt, Germany).

\subsection{Sample preparation}

A test solution of CF was prepared as follows; CF was initially dissolved in methanol $(10 \mathrm{mg} / \mathrm{mL})$. Next, this solution was diluted further by the addition of Milli-Q water to make a concentration of $40 \mathrm{mg} / \mathrm{L}$. A volume of $9 \mathrm{~mL}$ of the diluted sample solution in a glass vial was used for the UV irradiation experiment.

\subsection{UV irradiation experiment}

UV irradiation experiment was carried out in the light cabinet equipped with a black light lamp (20 W FL20S BLB, Toshiba, Tokyo, Japan). This lamp irradiates the UV mainly at $365 \mathrm{~nm}$ which is a component of sunlight. UV 
irradiation intensity at $365 \mathrm{~nm}$ was $600 \mu \mathrm{W} / \mathrm{cm}^{2} / \mathrm{sec}$ measured by means of the digital radiometer with a $365 \mathrm{~nm}$ sensor (UVX-36, UVP, Upland, CA, USA). Test samples were irradiated by the black light lamp at $20{ }^{\circ} \mathrm{C}$ (water depth was $3 \mathrm{~cm}$, distanced from the lamp source about $15 \mathrm{~cm}$ ). Irradiation times were up to 28 days. To clarify other factors, such as temperature and hydrolysis, had no contribution to the CF degradation, control samples were also prepared for the same condition but covered with the aluminum foil to shut out UV irradiation. All experiments were carried out in tetraplicate.

\subsection{HPLC analysis and UV spectral analysis}

HPLC analysis for monitoring the photodegradation of CF and the generation of its photoproducts was performed on Prominence HPLC system equipped with the reversephase column, which is composed of a LC-20AB pump, a SIL-20AC auto-sampler, a SPD-M20A photodiode array (PDA) detector with a LCsolution software, a CBM-20A system controller, a DGU-20A3 degasser, and a CTO-20A column oven (Shimadzu Corporation, Kyoto, Japan). The analytical column was a Shim-pack Arata C18 column (4.6×150 mm, $5 \mu \mathrm{m}$, Shimadzu Corporation). The column was kept at $40{ }^{\circ} \mathrm{C}$ during the analysis. An isocratic separation was achieved using the mobile phase consisting of methanol- $0.1 \%$ formic acid $(8: 2, \mathrm{v} / \mathrm{v})$. A mobile phase was prepared as follows; methanol $(800 \mathrm{~mL})$ and $0.1 \%$ formic acid $(\mathrm{v} / \mathrm{v}, 200 \mathrm{~mL})$ were mixed followed by the shaking and the degas. Flow rate was maintained at $1.0 \mathrm{~mL} / \mathrm{min}$, and the injection volume was $20 \mu \mathrm{L}$. Retention time of CF was $11.6 \mathrm{~min}$. Amounts of CF and its photoproducts evaluated by HPLC were shown as $\%$ of the initial compound before the UV irradiation.

The UV absorption spectra of CF and its photoproducts were recorded with a PDA detector. UV-irradiated CF solutions were injected to the HPLC system and UV spectra of the peaks of CF and its photoproducts were recorded under the HPLC conditions as mentioned above. Absorption-maximum wavelength $\left(\lambda_{\max }, \mathrm{nm}\right)$ of each peak was obtained from these results.

\subsection{Structure determination of CF photoproducts}

Identification of CF photoproducts was carried out using LC/MS system, which is composed of a LC-20AD pump, a SIL-20AC auto-sampler, a CBM-20A system controller, a DGU-20A5R degasser, and a CTO-20A column oven, a FCV$20 \mathrm{AH}_{2}$ valve unit, and a LCMS-8040 MS system equipped with ESI as the ionization source (Shimadzu Corporation). The whale system was operated using a LabSolutions software (Shimadzu Corporation). The analytical column was a Shim-pack Arata C18 column $(2.0 \times 50$ mm, $2.2 \mu \mathrm{m}$,
Shimadzu Corporation). The column was kept at $40^{\circ} \mathrm{C}$ during analysis. An isocratic separation was achieved using a mobile phase consisting of methanol- $0.1 \%$ formic acid $(8: 2, \mathrm{v} / \mathrm{v})$. Flow rate was maintained at $0.1 \mathrm{~mL} / \mathrm{min}$, and the injection volume was $10 \mu \mathrm{L}$. The mass spectrometer was run in the positive ion mode in the range of 50-1000 mass/ charge ratio $(\mathrm{m} / \mathrm{z})$. The following parameters were applied during analysis: nebulizer gas flow, $3.0 \mathrm{~L} / \mathrm{min}$; drying gas flow; $15.0 \mathrm{~L} / \mathrm{min}$; collision-induced dissociation (CID) gas, $230 \mathrm{kPa}$; desolvation line (DL) temperature, $200{ }^{\circ} \mathrm{C}$; heat block temperature, $200{ }^{\circ} \mathrm{C}$; and collision energy, $-20 \mathrm{~V}$. UV-irradiated sample for 3 days was analyzed by the scan mode and its result was compared with that of the control sample. Detected peaks from only UV irradiated sample were analyzed by the product ion scan mode to clarify the fragment patterns. When the peak was not detected or low by ESI-LC/MS/MS analysis in the positive ion mode, the analysis of scan mode and product ion scan mode were performed in the negative ion mode. Analysis parameters of LC and MS were the same to that of the positive ion mode except for collision energy, which was $+20 \mathrm{~V}$.

\subsection{Statistical analysis}

Data are expressed as the mean \pm standard deviation (S.D.). The homogeneity of variance was established using a oneway ANOVA. Statistical significance between two groups was estimated by the Student's $t$-test. The threshold for assessing significance were $p<0.001(\#)$ and $p<0.0001\left(^{*}\right)$ versus the control.

\section{Results and discussion}

\subsection{Evaluation of CF photodegradation}

In this study, photodegradation of CF in aqueous media was evaluated. There are several reports focused on the photodegradation of fibrates [17-19], but photodegradation of CF has not been investigated up to now. The chemical structure of CF and the result of its UV spectral analysis by the PDA detector are shown in Fig. 1. CF has a characteristic absorption between 210 and $300 \mathrm{~nm}$, showing $\lambda_{\max }$ values at $230 \mathrm{~nm}$ and $274 \mathrm{~nm}$ (Fig. 1). The UV absorption spectrum indicated that CF might be degraded by UV irradiation at longer wavelength. Secondary, HPLC analysis was performed for the evaluation of CF degradation. HPLC chromatograms of a control and a UV-irradiated CF solution for 3 days with a black light lamp are shown in Fig. 2. The retention time of CF was $11.6 \mathrm{~min}$. The peak of CF was decreased by UV irradiation with the generation of the several peaks derived from CF photoproducts (Peak 1-9 (denoted P1-P9)). However, contaminants of P2 and P7 


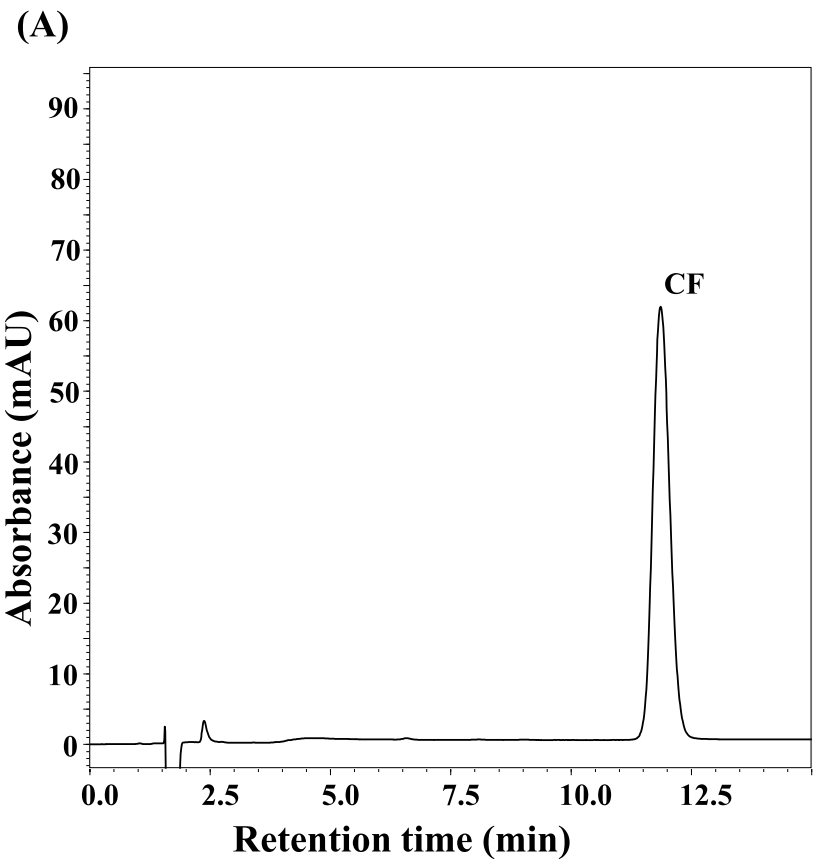

(B)

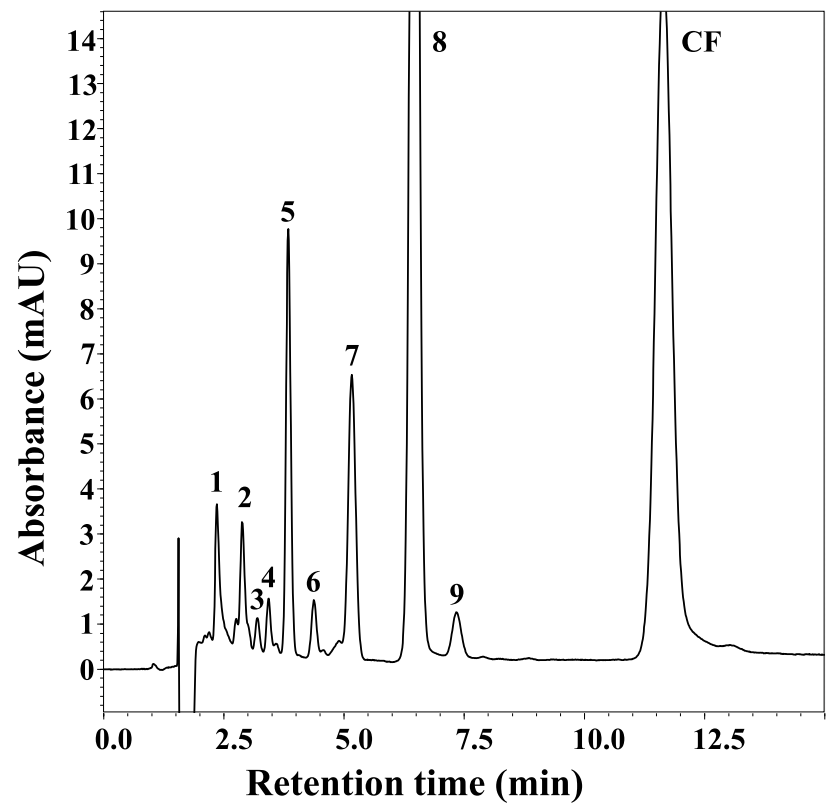

Fig. 2 HPLC analysis of CF in an aqueous media before (a) and after UV irradiation for 3 days (b). Detection wavelength: $254 \mathrm{~nm}$. Retention times of detected peaks were as follows; peak 1: $2.4 \mathrm{~min}$, peak 2: $2.9 \mathrm{~min}$, peak 3: $3.2 \mathrm{~min}$, peak 4: $3.4 \mathrm{~min}$, peak 5: $3.8 \mathrm{~min}$, peak 6: $4.4 \mathrm{~min}$, peak 7: $5.2 \mathrm{~min}$, peak 8: $6.5 \mathrm{~min}$, peak 9: $7.3 \mathrm{~min}, \mathrm{CF}$ : $11.6 \mathrm{~min}$

could not be separated, and the resolution of several peaks was not good although selectivity improvement was performed by changing HPLC conditions (column temperature, flow rate and both content and type of organic solvent, respectively). In the case that the content of the organic solvent in the mobile phase was low, the number of detected peaks of photoproducts in the HPLC chromatogram was not changed, as in this experiment, but the retention time of CF was over 60 min (data not shown). Furthermore, it is speculated that the contaminants of $\mathrm{P} 2$ and P7 would be minor photoproducts due to their amounts evaluated by HPLC. So, in this study, a mixture of methanol and water with the addition of $0.1 \%$ of formic acid $(8: 2, v / v)$ was used as the mobile phase, as shown in Fig. 2. These peaks eluted faster than CF indicating that CF photoproducts have higher polarities compared with CF. Also, P1 (retention time: $2.4 \mathrm{~min}$ ) was detected in both control and UV-irradiated samples, indicating that this is a potential impurity of CF. The generation of one photoproduct (P8) with a retention time of 6.5 min was significant, so this compound might be the main photoproduct of CF. In the UV irradiation experiment, residual amounts (\%) of CF and generation of its three photoproducts (P5, P7, and P8) are shown in Fig. 3. CF was rapidly degraded to $50 \%$ after 1 day UV irradiation (Fig. 3a). After that, CF was gradually degraded, and its peak was disappeared after 14 days irradiation. This result suggested that CF in commercial tablets and changed formulations without some shading film might be photodegraded by sunlight irradiation because the selected UV in this study is contained in sunlight. The residual amount of the control sample was not changed, indicating that only UV irradiation had a contribution on the CF degradation in this experiment. Several photoproducts were generated with a degradation of $\mathrm{CF}$, and the generation of $\mathrm{P} 5, \mathrm{P} 7$, and $\mathrm{P} 8$ were remarkable (Fig. 3b). Other photoproducts were also generated but their maximum amounts were less than $1 \%$ (data not shown). The residual amount of P7 was highest (4.67\%) at 4 days irradiation, and it was degraded completely as the same as in CF after 14 days irradiation. On the other hand, P5 and P8 were persisted then. Their residual amounts were highest at 14 days ( $12.94 \%$ and $42.69 \%$, respectively). After complete CF photodegradation, they were gradually degraded and disappeared after 28 days irradiation (data not shown). It is suggested that P5 and P8 might have more photostability compared with CF and other photoproducts. In this study, black light was used as a light source. This lamp irradiates the UV mainly at $365 \mathrm{~nm}$, which is a component of sunlight and whose irradiation intensity is as same to that of sunlight irradiation. It is possible that the photodegradation of clinofibrate might be induced by the sunlight irradiation.

\subsection{Structural determination of CF photoproducts}

For the structural determination of CF photoproducts, ESILC/MS/MS analysis was performed. Obtained $m / z$ values 


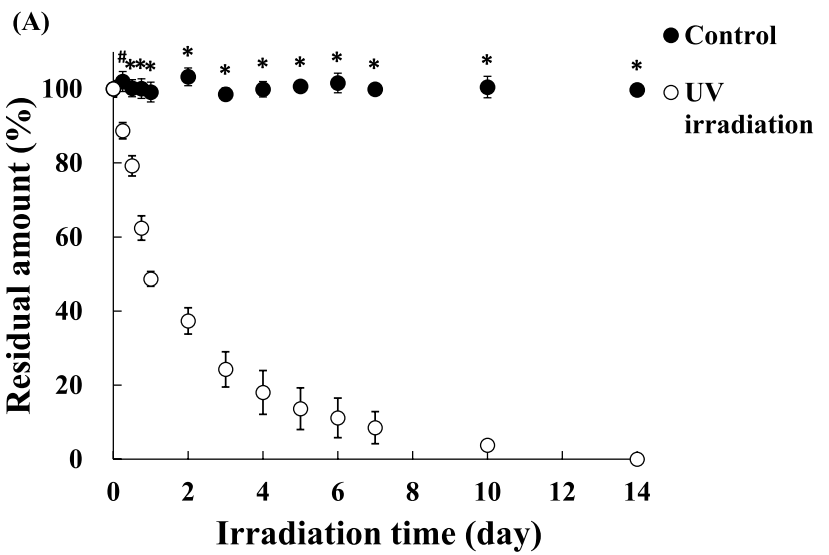

(B)

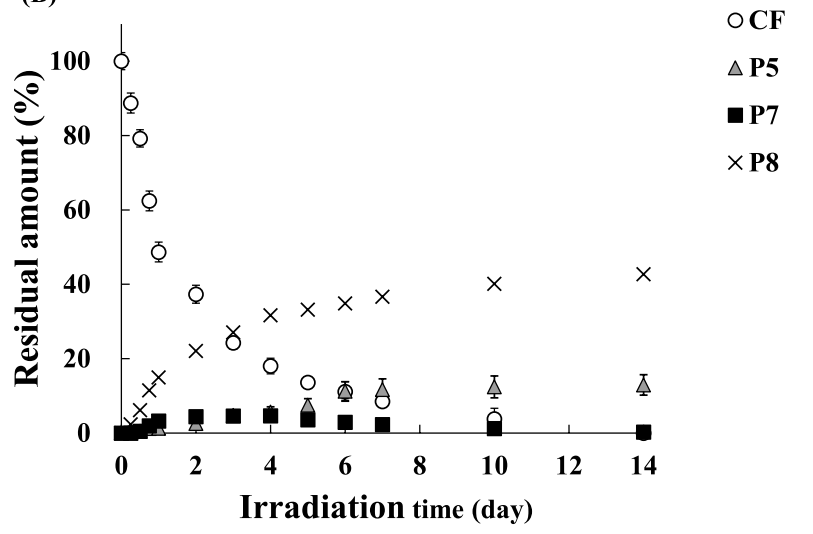

Fig. 3 Residual amounts (\%) of CF (a) and its three photoproducts (b) after UV irradiation. a CF (O) was monitored by means of HPLC. CF which was not exposed to UV served as the control $(\bullet)$. b Three photoproducts of CF (P5, P7 and P8) were monitored by means of HPLC. Values represent mean \pm S.D. $(n=4)$. "Difference compared with control $(p<0.001)$. ${ }^{*}$ Difference compared with control $(p<0.0001)$

for molecular ion peaks and fragment ion peaks are listed in Table 1. Obtained MS spectra and proposed fragmentation patterns are shown in supplementary data (Fig. S1).

Proposed chemical structures of nine photoproducts (P2-P9) based on the results of ESI-LC/MS/MS analysis and their IU pack names are shown in Table 1. It is revealed that $\mathrm{P} 7$ was composed of two photoproducts (P7-1 and P7-2) due to the results of ESI-LC/MS/MS analysis, which was supported by the results of HPLC analysis (Fig. 2). They were not separated under the LC condition. It is unclear that which photoproduct is main component of P7. On the other hand, the contaminants of P2 was not detected. Several fragment ions were detected when the analysis of CF was performed. The fragment ions with an $m / z$ value of 175 was significant, which was estimated as 1-(4-hydroxyphenyl)-1-cyclohexene. This product was formed by the elimination of 2-methylbutanoic acid and 2-methyl-2-phenoxybutanoic acid from CF. Also, the fragment ion with an $\mathrm{m} / \mathrm{z}$ value of 107 was proposed as $p$-quinomethane. Furthermore, the decarboxylation and further decomposition were observed as the fragmentation of CF. For example, the fragment ion with an $m / z$ value of 323 was formed by the decarboxylation and the following elimination of 2-methylbutanoic acid. On the other hand, the elimination of one and two 2-methylbutanoic acid from CF were observed in the negative ion mode analysis, resulting in the formation of the fragment ions with $\mathrm{m} / \mathrm{z}$ values of 367,267 , and 99 (data not shown).

Formation of P8 $(\mathrm{m} / \mathrm{z} 369)$ is postulated to occur from $C F$ through the elimination of 2-methylbutanoic acid. Major fragment ions of P8 were $m / z$ values of 175 and 107, which were the same as in CF. Also, it is speculated that further elimination of 2-methylbutanoic acid induces the generation of P3 ( $\mathrm{m} / z$ 267). In the MS spectrum of $\mathrm{P} 3$, the fragment ions with $\mathrm{m} / \mathrm{z}$ values of 173,93 , and 71 were proposed as anions of 1-(4-hydroxyphenyl)1-cyclohexene, phenol, and pentane. The chemical structure of P8 was proposed as 2-(4-(1-(4-hydroxyphenyl) cyclohexyl)phenoxy)-2-methylbutanoic acid, and that of P3 was proposed as 4,4'-(cyclohexane-1,1-diyl)diphenol. The results of UV spectral analysis indicated that CF, P8, and P3 showed a similar UV absorption around $270 \mathrm{~nm}$ (Fig. S2, $\lambda_{\max }: 274 \mathrm{~nm}, 276 \mathrm{~nm}$ and $273 \mathrm{~nm}$, respectively). These three compounds had the same chromophore $\left(1,1^{\prime}\right.$-biphenyl-cyclohexane) resulting in the similar UV absorption.

In the MS spectrum of protonated P6 ( $\mathrm{m} / \mathrm{z} 353)$, the formation of fragment ion with an $m / z$ value of 175 was significant as the same to CF and other photoproducts. The fragment ion with an $m / z$ value of 217 was proposed as 1-(4-propoxyphenyl)-1-cyclohexene. The $m / z$ value of P6 was smaller than that of $\mathrm{P} 8$ by 16 , which is corresponded to the molecular weight of oxygen. It is suggested that P6 might be a dehydroxy-form of P8. From these results, it is tempting to speculate that the chemical structure of P6 is 2-methyl-2-(4-(1-phenylcyclohexyl)phenoxy)butanoic acid.

The $m / z$ value of P9 was 409 in the negative ion mode. The generation of fragment ions with $m / z$ values of 309 and 99 indicated that the elimination of 2-methylbutanoic acid from P9 occurred. Additional fragment ion with an $\mathrm{m} / \mathrm{z}$ value of 267 might be formed through the elimination of the propyl group from the fragment ion with an $\mathrm{m} / \mathrm{z}$ value of 309 , which was corresponded to the obtained $\mathrm{m} / \mathrm{z}$ value of $\mathrm{P} 5$. In the MS spectrum of $\mathrm{P} 5$, major fragment ions were $m / z$ value of 175 and 107 , which were the same as in CF and other photoproducts. From these results, it is postulated that the structure of P9 is 2-methyl-2-(4-(1-(4propoxyphenyl)cyclohexyl)phenoxy)butanoic acid and the structure of P5 is 4-(1-(4-propoxyphenyl)cyclohexyl) phenol. 
Table 1 Observed $\mathrm{m} / \mathrm{z}$ values for the detected ions, major fragments and chemical structures of $\mathrm{CF}$ and its photoproducts

\begin{tabular}{|c|c|c|c|c|c|}
\hline Peak & ESI & $\begin{array}{l}\text { Observed } \\
m / z \text { value }\end{array}$ & Fragment ions & Chemical structure & IU pack naming \\
\hline CF & $(+)$ & 469 & $\begin{array}{l}55,83,107,161,175,189,229,275 \\
\quad 323,351,405,423\end{array}$ & & $\begin{array}{l}\text { 2,2'-((Cyclohexane-1,1-diylbis(4,1- } \\
\text { phenylene))bis(oxy))bis(2-methylbuta- } \\
\text { noic acid) }\end{array}$ \\
\hline P2 & $(+)$ & 257 & $107,121,147,163,175$ & & 4-([1,1'-Bi(cyclohexan)]-1'-en-1-yl)phenol \\
\hline P3 & $(-)$ & 267 & $71,93,173$ & & 4,4'-(Cyclohexane-1,1-diyl)diphenol \\
\hline P4 & $(-)$ & 291 & $99,173,191$ & & $\begin{array}{l}\text { 2-(4-(n-Hydroxycyclohexyl)phenoxy)- } \\
\text { 2-methylbutanoic acid }\end{array}$ \\
\hline P5 & $(+)$ & 311 & $107,175,269$ & & 4-(1-(4-Propoxyphenyl)cyclohexyl)phenol \\
\hline P6 & $(+)$ & 353 & $107,175,217$ & & $\begin{array}{l}\text { 2-Methyl-2-(4-(1-phenylcyclohexyl)phe- } \\
\text { noxy)butanoic acid }\end{array}$ \\
\hline P7-1 & $(+)$ & 357 & $83,107,121,613,175,257,283,311$ & & $\begin{array}{l}\text { 2-(4-([1,1'-Bi(cyclohexan)]-1'-en-1-yl) } \\
\text { phenoxy)-2-methylbutanoic acid }\end{array}$ \\
\hline P7-2 & $(-)$ & 425 & $99,283,325,339,383$ & & $\begin{array}{l}\text { 2-Methyl-2-(4-(1-(4-propoxyphenyl)-n- } \\
\text { hydroxycyclohexyl)phenoxy)butanoic } \\
\text { acid }\end{array}$ \\
\hline P8 & $(+)$ & 369 & $55,83,101,107,175,323$ & $\begin{array}{l}\mathrm{HOOC}^{-} \\
\mathrm{H}_{3} \mathrm{CH}_{2} \mathrm{C}\end{array}$ & $\begin{array}{l}\text { 2-(4-(1-(4-Hydroxyphenyl)cyclohexyl) } \\
\text { phenoxy)-2-methylbutanoic acid }\end{array}$ \\
\hline P9 & $(+)$ & 409 & $99,267,309$ & & $\begin{array}{l}\text { 2-Methyl-2-(4-(1-(4-propoxyphenyl) } \\
\text { cyclohexyl)phenoxy)butanoic acid }\end{array}$ \\
\hline
\end{tabular}

It is speculated that the formation of P7-2 $(\mathrm{m} / \mathrm{z}$ 425) might be derived on the oxidation of $P 9(\mathrm{~m} / z$ 409). The generation of fragment ions with the $m / z$ values of 383 and 283 were significant. The fragment ion with an $\mathrm{m} / \mathrm{z}$ value of 283 might be formed through the elimination of 2-methylbutanoic acid from the fragment ion with an $\mathrm{m} / \mathrm{z}$ value of 383 , which was corresponded to the obtained $\mathrm{m} / \mathrm{z}$ value of hydroxyl-form of P8. Also, it is speculated that the elimination of the propyl group from P7-2 occur the formation of its fragment ion with an $\mathrm{m} / \mathrm{z}$ value of 383. Other fragment ions with $\mathrm{m} / \mathrm{z}$ values of 325 and 339 were proposed as the compounds having the hydroxyl group in the cyclohexane ring (Fig. $\mathrm{S} 1 \mathrm{H})$. There results suggest that the structure of P7-2 is 2-methyl-2-(4-(1-(4propoxyphenyl)-n-hydroxycyclohexyl)phenoxy)butanoic acid. Three fragment ions with the $\mathrm{m} / \mathrm{z}$ values of 191,173 , and 99 were detected in the MS spectrum of P4 $(\mathrm{m} / \mathrm{z} 291)$ in the negative ion mode. These fragment ions 
were proposed as anions of 1-(4-hydroxyphenyl)-hydroxycyclohexane, 1-(4-hydroxyphenyl)-1-cyclohexene and 2-methylbutanoic acid. It is suggested that the fragment ion with an $\mathrm{m} / \mathrm{z}$ value of 191 was generated after the elimination of 2-methylbutanoic acid from P4. The structure of P4 is proposed as 2-(4-(n-hydroxycyclohexyl)phenoxy)2-methylbutanoic acid. In the chemical structure of P7-2 and $\mathrm{P} 4$, the position of hydroxy group in the cyclohexane ring was not investigated in this experiment.

In the MS spectrum of protonated P7-1 ( $\mathrm{m} / \mathrm{z} 357)$, the generation of the fragment ion with an $m / z$ value of 257 , which was corresponded to the obtained $m / z$ value of $P 2$, was significant. It is suggested that $P 2$ might be formed by the elimination of 2-methylbutanoic acid from P7-1. The formation of fragment ion with an $m / z$ value of 175 was significant in the MS spectrum of $\mathrm{P} 2$. This product seems to be formed after the elimination of cyclohexene from P2. The fragment ion with an $m / z$ value of 81 , which was proposed as an anion of cyclohexene, was observed in the negative ion mode analysis (data not shown). In the case of P7-1, the elimination of 2-methylbutanoic acid and cyclohexene resulted in the formation of the fragment ion with an $\mathrm{m} / \mathrm{z}$ value of 175 . From these results, it is speculated that the structure of P7-1 is 2-(4-([1,1'-bi(cyclohexan)]-1'-en-1-yl) phenoxy)-2-methylbutanoic acid, and the structure of $\mathrm{P} 2$ is 4-([1,1'-bi(cyclohexan)]-1'-en-1-yl)phenol. As a result of structural determination, the chemical structures of one main photoproduct and several minor photoproducts of CF were clarified.

\subsection{Proposed CF photodegradation pathway}

The speculation of the photodegradation pathway is important for the understanding of photochemical feature of the chemical compound. In this study, we proposed the three photodegradation pathways of CF to its photoproducts (Figs. 4, 5). The elimination of 2-methylbutanoic acid from excited CF induced by UV irradiation is the main pathway of the generation of P8 (Fig. 4). Further elimination of 2-methylbutanoic acid from P8 induces the generation of P3. Based on the results of HPLC analysis (Fig. 2b), $\mathrm{P} 8$ seems to be the main photoproduct of CF generated by the UV irradiation. It is speculated that the generation of $\mathrm{P} 3$ has a little contribution for the degradation of P8 because the amount of P3 was not increased with the decrease of P8 amount (Fig. 3b). It is possible that secondary and further products (such as dimer, advanced elimination form, and addition form of P8) might be generated with the degradation of $\mathrm{P} 8$, but they were not detected in the HPLC analysis.

Also, the elimination of 2-hydroxy-2-methylbutanoic acid from CF resulted in the generation of $\mathrm{P} 6$, and the elimination of acetic acid from CF resulted in the generation<smiles>[3H]CC(C)(Oc1ccc(C2(c3ccc(OC(C)(CC)C(=O)O)cc3)CCCCC2)cc1)C(=O)O</smiles><smiles>CC=C(C)C(=O)O</smiles><smiles>CC(C)C(C)(Oc1ccc(C2(c3ccc(O)cc3)CCCCC2)cc1)C(=O)O</smiles><smiles>CC=C(C)C(=O)O</smiles><smiles>Oc1ccc(C2(c3ccc(O)cc3)CCCCC2)cc1</smiles>

Fig. 4 Proposed photodegradation pathways for P3 and P8 from CF

of P9 (Fig. 5). Also, further degradation pathways were speculated as follows; the elimination of propanol from $\mathrm{P} 9$ contributes to the generation of $\mathrm{P} 6$, and the elimination of 2-methylbutanoic acid from P9 contributes to the generation of P5. The residual amount of P5 was gradually increased with the degradation of CF (Fig. 3b), indicating that the conversion of CF to $\mathrm{P} 9$ is a secondary major photodegradation pathway. Also, the oxidation of the cyclohexane ring of $\mathrm{P} 9$ contributes to the generation of $\mathrm{P} 7-2$, and 


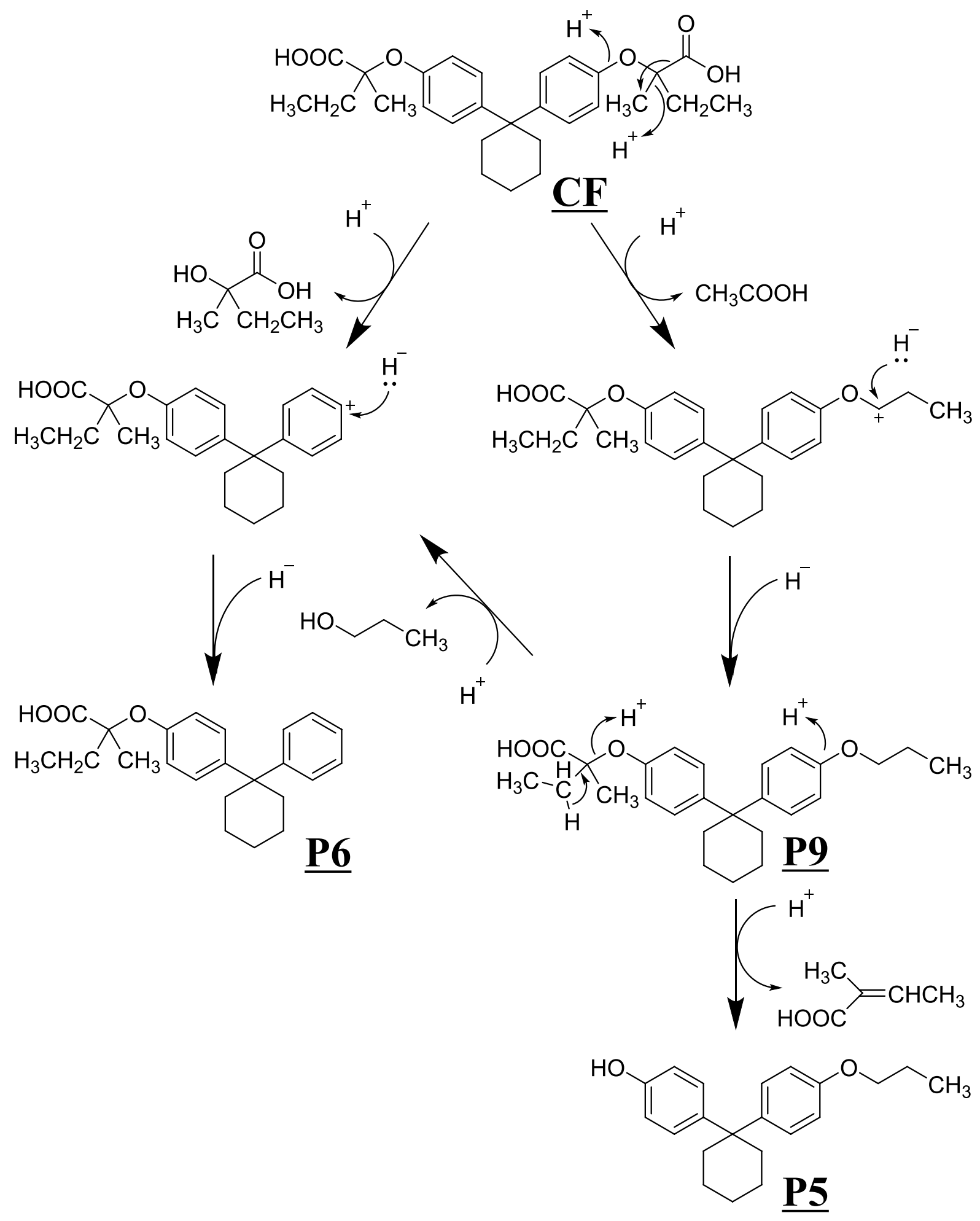

Fig. 5 Proposed photodegradation pathways for P5, P6 and P9 from CF

P4 is generated by the elimination of the propoxyphenyl group from P7-2 (Fig. 6). The generation of P7-1 is induced by the addition of cyclohexene, which might be generated by the elimination of two phenyl groups from CF and other photoproducts, after the elimination of phenol from P8 or that of 2-methyl-2-phenoxybutanoic acid from CF (Fig. 7). Other elimination reaction might contribute to the generation of 2-(4-cyclohexylphenoxy)-2-methylbutanoic 
<smiles>CCCOc1ccc(C2(c3ccc(OC(C)(C)C(=O)O)cc3)CCCCC2)cc1</smiles><smiles>CC1[CH-]CC(C)C1(C)C</smiles><smiles>CCCOc1ccc(C2(c3ccc(OC(C)(CC)C(=O)O)cc3)CCCCC2)cc1</smiles><smiles>CCCCc1ccc(OCC)cc1</smiles><smiles>CCC(C)(Oc1ccc(C2CCCCC2)cc1)C(=O)O</smiles>

$\underline{\text { P4 }}$

Fig. 6 Proposed photodegradation pathways for P7-2 and P4 from P9

acid, which is a precursor form of P7-1. The elimination of 2-methylbutanoic acid from P7-1 resulted in the formation of $\mathrm{P} 2$. It is possible that other photoproducts might be generated from $C F$, but they were not detected or determined in this experiment.

Predicted photodegradation pathways of CF are different from that of other fibrates, including clofibric acid and bezafibrate [17-19]. CF has no chloride, and there is no intermediate such as 4-chlorophenol in the photodegradation pathway. In the case of fibrate containing chloride, generated chlorine radical and chlorine species from parent compounds enhanced their photodegradation [17], indicating that main photodegradation pathway of other fibrates is indirect photodegradation mediated by radical species and active intermediates. On the other hand, proposed photodegradation pathways suggested that main photodegradation pathway was direct photodegradation, not indirect photodegradation, such as elimination of a part of the structure.

It is proposed that the elimination of 2-methylbutanoic acid is an important step for the photodegradation of CF. This elimination reaction was induced easily for the formation of $\mathrm{P} 8$, resulting in that the residual amount of both compounds were the same after 3 days of UV irradiation (Fig. 3b). Interestingly, the photodegradation of CF was gradually suppressed after the generation of P5 and P8, indicating that they react as photoprotective agents for $C F$. $\mathrm{P} 5$ and P8 were remained after the complete degradation of CF by UV irradiation. In general, the photodegradation of substrate is promoted when its concentration is low due to the increasing of irradiation efficiency for the reaction solution. Our previous studies showed that photodegradation of phenytoin was suppressed by its main photoproduct benzophenone, which is well known as a UV filtering agent [20]. It is possible that $\mathrm{P} 5, \mathrm{P} 8$, or other potential photoproducts of $C F$, which are generated from $C F$ among the UV irradiation, interrupt the UV absorption of CF in a test solution, resulting in the slower photodegradation of CF.

\section{Conclusion}

In this study, the photodegradation of CF induced by UV irradiation was evaluated, and the chemical structures of its photoproducts were evaluated. The amount of CF was gradually decreased and completely degraded after 14 days of irradiation. Furthermore, the main photoproduct of CF (P8) was generated by the elimination of a 2-methylbutanoic acid, which was more photostable than the parent compound. This is the first study showing the CF photodegradation. The obtained results will be helpful for the additional research focused on the evaluation of biological activities of CF photoproducts, photostability of CF in commercial tablets and changed formulations, and the photostabilization of them. It is important for the photodegradable pharmaceuticals to investigate their photostability for the appropriate handling of them. Further research is needed to clarify the effect of photo-irradiation on the photosensitive pharmaceuticals, of which their photochemical behaviors are not well known. 
<smiles>CCCCC1(c2ccc(O)cc2)CCCCC1(c1ccc(OC(C)(CC)C(=O)O)cc1)C1CCCCC1</smiles>

$\underline{\text { P8 }}$<smiles>CCC(C)(Oc1ccc(C2(c3ccc(OC(C)(C)C(=O)O)cc3)CCCCC2)cc1)C(=O)C1=CCCCC1</smiles>

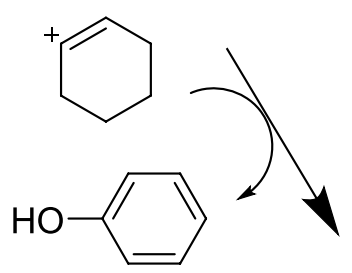<smiles>CCC</smiles><smiles>[C+]CCCC</smiles><smiles>C=COC(C)(CC)COCC</smiles><smiles>Cc1ccc(C2(C3=CC=CCC3)CCCCC2)cc1</smiles><smiles>CC[C@H](C)[C@H](C)CC1=CCCCC1</smiles>

$\mathrm{H}$

\section{P7-1}<smiles>CC=C(C)C(=O)O</smiles><smiles>Oc1ccc(C2(C3=CCCCC3)CCCCC2)cc1</smiles>

Fig. 7 Proposed photodegradation pathways for P7-1 and P2 from CF and P8

Funding This study was supported by JSPS KAKENHI Grant Number JP 20 K15980.

\section{Declarations}

Conflict of interest There is no conflict of interest.
Open Access This article is licensed under a Creative Commons Attribution 4.0 International License, which permits use, sharing, adaptation, distribution and reproduction in any medium or format, as long as you give appropriate credit to the original author(s) and the source, provide a link to the Creative Commons licence, and indicate if changes were made. The images or other third party material in this article are included in the article's Creative Commons licence, unless indicated otherwise in a credit line to the material. If material is not included in the article's Creative Commons licence and your intended use is not permitted by statutory regulation or exceeds the permitted use, you will need to obtain permission directly from the copyright holder. To view a copy of this licence, visit http://creativecommons. org/licenses/by/4.0/.References 
1. International Conference on Harmonisation Steering Committee (2003)ICH harmonized tripartite guideline stability testing of new drug substances and products $Q 1 A(R 2)$

2. Sheu M-T, Ho H-O, Wang P-Y, Liou Y-B, Wu A-B (2003) Photolysis of NSAIDs. I. Photodegradation products of carprofen determined by LC-ESI-MS. J Chromatogr Sci 41:200-204

3. Garcia-Galan MJ, Diaz-Cruz MS, Barcelo D (2012) Kinetic studies and characterization of photolytic products of sulfamethazine, sulfapyridine and their acetylated metabolites in water under simulated solar irradiation. Water Res 46:711-722

4. Uwai K, Tani M, Ohtake Y, Abe S, Maruko A, Chiba T, Hamaya Y, Ohkubo Y, Takeshita M (2005) Photodegradation products of propranolol: the structures and pharmacological studies. Life Sci 78:357-365

5. DellaGreca $M$, lesce $M R$, Previtera $L$, Rubino $M$, Temussi $F$ (2004) A new photoproduct of the drug furosemide in aqueous media. Environ Chem Lett 2:155-158

6. Dong MM, Trenholm R, Rosario-Ortiz FL (2015) Photochemical degradation of atenolol, carbamazepine, meprobamate, phenytoin and primidone in wastewater effluents J. Hazard Mater 23:216-223

7. International Conference on Harmonization Steering Committee (1996) ICH harmonized tripartite guideline photostability testing of new drug substances and products Q1B

8. Xu J, Hao Z, Guo C, Zhang Y, He Y, Meng W (2014) Photodegradation of sulfapyridine under simulated sunlight irradiation: kinetics, mechanism and toxicity evolvement. Chemosphere 99:186-191

9. Konstantinou IK, Sakkas VA, Albanis TA (2002) Photocatalytic degradation of propachlor in aqueous $\mathrm{TiO} 2$ suspensions. Determination of the reaction pathway and identification of intermediate products by various analytical methods. Water Res 36:2733-2742

10. Petrovic M, Barcelo D (2007) LC-MS for identifying photodegradation products of pharmaceuticals in the environment. Trends Anal Chem 26:486-493

11. Miolo G, Marzano C, Gandin V, Palozzo AC, Dalzoppo D, Salvador A, Caffieri S (2011) Photoreactivity of 5-fluorouracil under UVB light: photolysis and cytotoxicity studies. Chem Res Toxicol 24:1319-1326
12. Zhao Y, Shi M, Ye JH, Zheng XQ, Lu JL, Liang YR (2015) Photoinduced chemical reaction of trans-resveratrol. Food Chem 171:137-143

13. Koshima H, Fukano M, Ojima N, Johmoto K, Uekusa H, Shiro M (2014) Absolute asymmetric photocyclization of triisopropylbenzophenone derivatives in crystals and their morphological changes. J Org Chem 79:3088-3093

14. Kawabata K, Mizuta Y, Ishihara K, Takato A, Oshima S, Akimoto S, Inagaki M, Nishi H (2019) Structure determination of naproxen photoproducts in the tablet generated by the UV irradiation. Chromatography 40:157-162

15. Ishidori M, Lavorgna M, Nardelli A, Parrella A, Previtera L, Rubino M (2005) Ecotoxicity of naproxen and its phototransformation products. Sci Total Environ 348:93-101

16. Della Greca $M$, Brigante $M$, Isidori $M$, Nardelli A, Previtera $L$, Rubino M, Temussi F (2003) Phototransformation and ecotoxicity of the drug Naproxen-Na. Environ Chem Lett 1:237-241

17. Avetta $P$, Fabbri $D$, Minella $M$, Brigante $M$, Maurino $V$, Minero C, Pazzi M, Vione D (2016) Assessing the phototransformation of diclofenac, clofibric acid and naproxen in surface waters: model predictions and comparison with field data. Water Res 105:383-394

18. Vargas F, Canudas N, Miranda MA, Boscá F (1993) In vitro phototoxicity of clofibrate. Photochemical and photohemolytic studies on its metabolite clofibric acid. Photochem Photobiol 58:71-76

19. Regulska E, Karpińska J (2014) Investigation of novel material for effective photodegradation of bezafibrate in aqueous samples. Environ Sci Pollut Res Int 21:5242-5248

20. Kawabata K, Akimoto S, Nishi H (2020) Photo-conversion of phenytoin to ecotoxicological substance benzophenone by ultraviolet light irradiation in aqueous media. Chromatography 41:51-58

Publisher's Note Springer Nature remains neutral with regard to jurisdictional claims in published maps and institutional affiliations. 